\title{
S-100 Protein positive cells in nasopharyngeal carcinoma (NPC): absence of prognostic significance
}

\section{A clinicopathological and immunohistochemical study of 40 cases}

\author{
F.J. Vera-Sempere ${ }^{1}$, C. Micheau ${ }^{2}$, and A. Llombart-Bosch ${ }^{1}$ \\ ${ }^{1}$ Facultad de Medicina de Valencia, Departamento de Patologia, Blasco Ibañez 17, Valencia, E-46010, Spain \\ ${ }^{2}$ Institut Gustave Roussy (IGR), Département d'Anatomie Pathologique, Unité d'Histopathologie " A", \\ Rue Camille Desmoulins, F-94900 - Villejuif, France
}

Summary. An immunohistochemical study of S100 protein in 43 nasopharyngeal carcinomas (NPC) of known clinical evolution (33 primary and 10 metastatic) is presented. Sixty per cent of primary site cases as well as all metastatic forms showed S-100 protein positive cells intermingled with tumour cells. These S-100 positive elements were identified as Langerhans cells. No significant differences were found when correlating $\mathrm{S}-100$ protein positivity and histological NPC variants, neither in age nor in sex of patients. Statistical analysis failed to demonstrate any positive correlation between S-100 protein reactivity and clinical survival.

Key words: S-100 Protein - Langerhans cells - Nasopharyngeal carcinoma - Prognosis

\section{Introduction}

In recent years the histopathological approach to nasopharyngeal carcinoma (NPC) has been focused not only on its controversial classification (Micheau et al. 1981; Elouaret et al. 1986; Micheau 1986) but also on its histological and histochemical features, some of which may display prognostic significance (Shanmugaratnam et al. 1979; Shaw et al. 1985; Elouaret et al. 1986; Nomori et al. 1986).

Within this context the S-100 antigen seems to have a specific value in this tumour: Nomori et al. (1986) have postulated that the presence of S-100 protein positive cells ( $\mathrm{T}$-zone histiocytes, Langerhans' cells and their precursors) within the NPC could be correlated with a prolonged survival rate. In order to confirm this finding we have under-

Offprint requests to: F.J. Vera-Sempere at the above address taken a retrospective study of 40 cases of NPC (primary and metastatic tumours) in which a complete follow-up was available. A comparative analysis between the histological type of NPC, presence of $S-100$ protein positive cells and survival is presented.

\section{Materials and methods}

This analysis comprises 43 specimens of nasopharyngeal carcinoma (NPC) from the files of the Institut Gustave Roussy, selected on the basis of adequate follow-up of the patients: 33 were primary tumours and 10 were metastatic to cervical lymph nodes. According to the UICC-classification (1978) the primary tumours consisted of 2 cases of Stage I, 6 of Stage II, 12 of Stage III, 13 of Stage IV. Cervical lymph nodes consisted of 3 Stage III and 7 Stage IV cases. Three cases were excluded because of scanty biopsy material or because of the presence of artifacts in the immunohistochemical technique.

Patients were 9 female and 34 male (a ratio of 1 to 3.7 ) and an age range between 10 years and 62 years with a mean of 38,7 years; 13 of the patients were of Maghreb origin and 1 Southeast Asian, the rest being French. The clinical follow-up ranged from 12 month to 144 months (the mean follow-up being 42 months per patient). During this period, 23 out of 43 patients died as a consequence of tumour progression. All patients were submitted to local radiotherapy, occasionally associated with regional surgery.

The tumour cases were classified by their most oustanding histological feature using the classification proposed by $\mathrm{Mi}$ cheau et al. (1981): 34 were considered to be undifferentiated carcinomas of nasopharyngeal type (UCNT) while 6 were diagnosed as the squamous cell carcinoma variant.

Immunohistochemistry for S-100 protein was performed on formaldehyde-fixed, paraffin-embedded tissue sections (5 microns), using the unlabeled peroxidase - antiperoxidase (PAP) staining technique of Sternberger et al. (1970). The sections were deparaffinized and hydrated, then soaked in $1 \%$ hydrogen peroxide in absolute methanol at room temperature for $30 \mathrm{~min}$ to eliminate endogenous peroxidase activity. After washing in Tris-saline buffer $(0.05 \mathrm{M}, \mathrm{pH} 7.6)$, the sections were treated for $20 \mathrm{~min}$ with normal horse serum $(20 \%)$, and later were incubated at room temperature for $30-45 \mathrm{~min}$, with a primary antibody to S-100 protein (1/300 dilution). Anti-rabbit swine antibody (1/100 dilution) and rabbit PAP complex (1/100 dilution) and washing in Tris-saline were applied sequentially; 
3-3'-diaminobenzidine tetrahydrochloride (DAB) fresh solution $(0.05 \%)$ in Tris-ClH $0.2 \mathrm{M}$, pH 7.3 added with hydrogen peroxide $(0.03 \%)$ were used for visualization. The nuclei were counterstained with Harris' hematoxylin and the sections were mounted in synthetic resin (Entellan, Merck, FRG). All the immunosera employed were purchased from Dakopatts Ltd. Copenhagen, Denmark. The specificity of the immunostaining was confirmed by replacing the primary antiserum with nonimmune rabbit serum according to Nadji and Morales (1983). As positive control tissue, different biopsy specimens containing structures with well-known S-100 positivity (cutaneous nevus, malignant melanomas and peripheral nerve) (Stefansson et al. 1982; Springall et al. 1983) were employed.

Sliced sections of 10 primary and 5 metastatic cases of NPC were also studied by PAP using rabbit anti-human muramidase (Dakoppats) (1/500 dilution), mouse monoclonal anti-HLADR (Dakoppats) (1/50 dilution) and rabbit anti-Peanut Lectin (PNL) (Dakoppats) (1/1000 dilution).

The S-100 protein positivity was evaluated according to Nomori's scheme (Nomori et al. 1986) as follows: (-) no cells, $(+) 1$ cell to 5 cells, $(++)$ more than 5 cells per field, calculated by $200 \times$ magnification. When the cell density varied from area to area, the densest area was selected.

The correlation between prognosis and the S-100 protein reactivity was reviewed in 30 primary tumour sites by means of survival curves for homogeneous cases of S-100 positivity. Survival curves were obtained by the Kaplan-Meier method (1958) and the significant relationship evaluated by the log-rank test according to Mantel and Haenszel (1959).

\section{Results}

In 28 out of the 40 cases of NPC reviewed immunohistochemically, $\mathrm{S}-100$ protein positive cells were present. In 18 primary NPC cases $(60 \%) \mathrm{S}$ 100 protein reactivity was present; the 10 cases of metastatic lymph nodes also showed positivity in variable amounts. Of these eighteen S-100 NPC of primary site, 6 cases were classified as $+(1$ cell to 5 cells positive per field), and 12 as ++ (more than 5 cells per field). In the metastatic group three cases showed isolated positive cells only in the lymph node stroma while the remaining seven cases revealed positivity not only in the lymph node stroma but also intermingled with tumour cells.

No positivity for S-100 was found in the tumour cells of the primary tumours or in the neoplastic cells of metastases. The positive cells appeared to be intermingled between the tumour cells or to surround the neoplastic nests (Fig. 1a, b). They showed irregular shape and size, displayed dendritic features which included extended cytoplasmic processes in variable number and length.
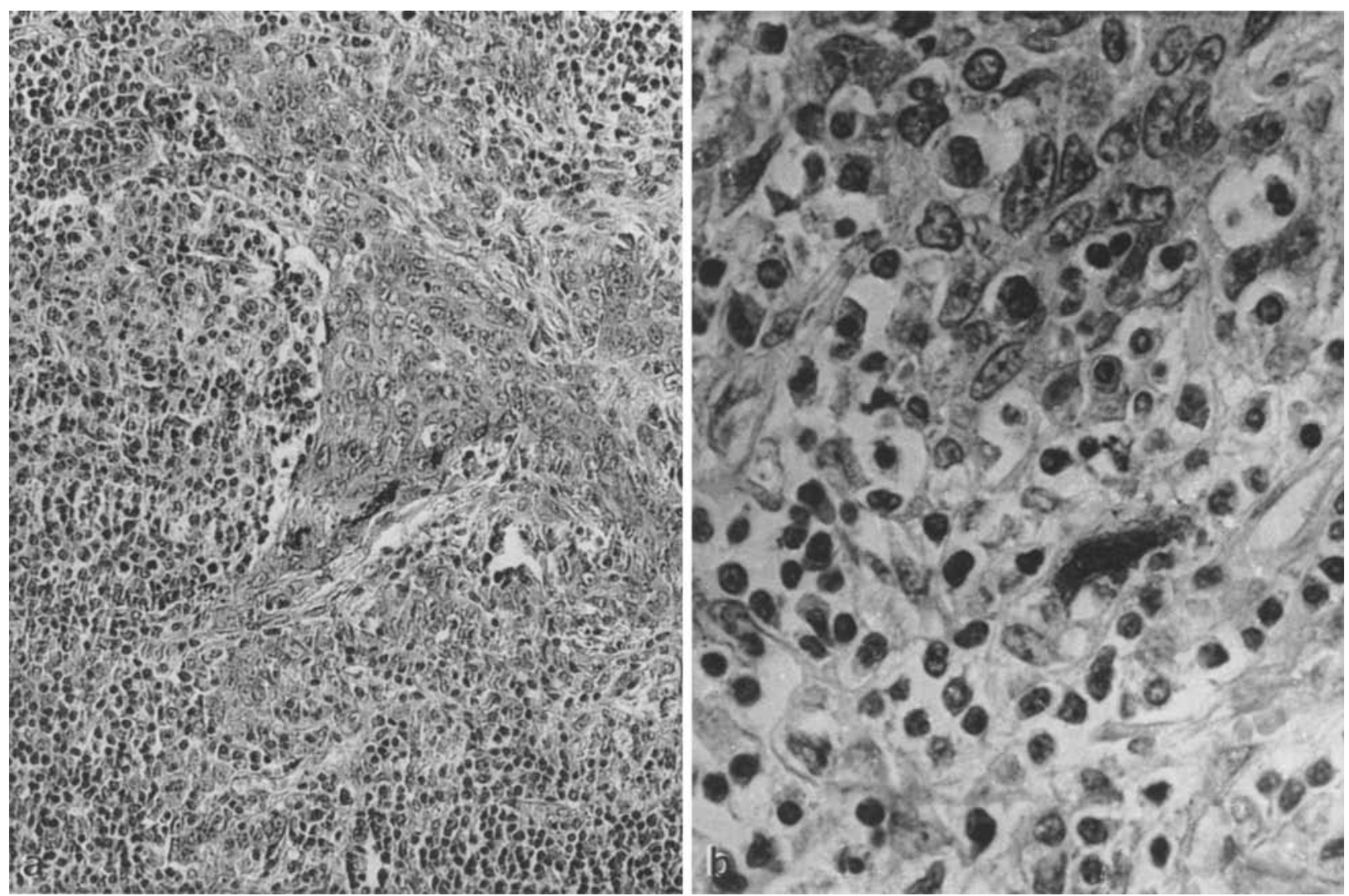

Fig. 1. a Undifferentiated nasopharyngeal carcinoma showing several S-100 protein positive cells located within the tumour nest. PAP S-100 $200 \times$. b Undifferentiated carcinoma of nasopharyngeal type. Isolated S-100 protein cell located among tumour cells shows an irregular profile of dendritic appearance. PAP S-100 $400 \times$ 
Table 1. S-100 Protein positive density in NPC and histological type

\begin{tabular}{llrrr}
\hline Location & Histological types & \multicolumn{2}{l}{$\begin{array}{l}\text { Density of S-100 protein } \\
\text { positive cells }\end{array}$} \\
\cline { 3 - 5 } & & - & + & ++ \\
\hline P.S. & U.C.N.T. & 11 & 4 & 11 \\
& S.C.C. & 1 & 2 & 1 \\
\hline Total No. & & 12 & 6 & 12 \\
\hline M & U.C.N.T. & 0 & 2 & 6 \\
& S.C.C. & 0 & 1 & 1 \\
\hline Total No. & & 0 & 3 & 7 \\
\hline
\end{tabular}

P.S. = Primary Site; $M=$ Metastatic cervical lymph node; U.C.N.T. = Undifferentiated Carcinoma Nasopharyngeal Type S.C.C. $=$ Squamous Cell Carcinoma

Table 2. S-100 Protein positive density in NPC of primary site correlated with sex/age of patients

\begin{tabular}{l}
$\begin{array}{l}\text { Density of S-100 } \\
\text { positive cells }\end{array}$ \\
\hline
\end{tabular}

\begin{tabular}{|c|c|c|c|c|}
\hline \multicolumn{5}{|c|}{ Sex (No. of patients) } \\
\hline M & 7 & 4 & 10 & 21 \\
\hline $\mathrm{F}$ & 5 & 2 & 2 & 9 \\
\hline $\begin{array}{c}\text { Age (mean) } \\
\text { (SD) }\end{array}$ & $\begin{array}{r}37.9 \\
( \pm 12.1)\end{array}$ & $\begin{array}{c}36 \\
( \pm 23.7)\end{array}$ & $\begin{array}{r}49.3 \\
( \pm 11.5)\end{array}$ & \\
\hline
\end{tabular}

\begin{tabular}{llll}
\hline Total No. & 12 & 6 & 12 \\
\hline
\end{tabular}

$\mathrm{SD}=$ Standard Deviation

The cells were located close to the malignant epithelial component. Only very occasionally were positive S-100 protein cells seen in a major conglomeration within one tumour area, but with an uneven distribution. These areas of greater S-100 positive cell density did not possess any special histological features when reviewed with conventional stains. Nevertheless it was clearly seen that the S100 protein reactive cells were more numerous close to the neoplastic tissue than in the neighbouring lymphoid infiltrate.

Similarly, in seven cases of primary NPC which also contained a certain amount of non-neoplastic tissue of the nasopharynx, $\mathrm{S}-100$ positive elements were found: the cells were located within the malphigian epithelium at a basal and suprabasal level as well as in isolated fashion within the subepithelial lymphoid tissue. When located on the stratified epithelium the $\mathrm{S}-100$ protein positive cells displayed a branched structure, which is characteristic of Langerhans' cells.

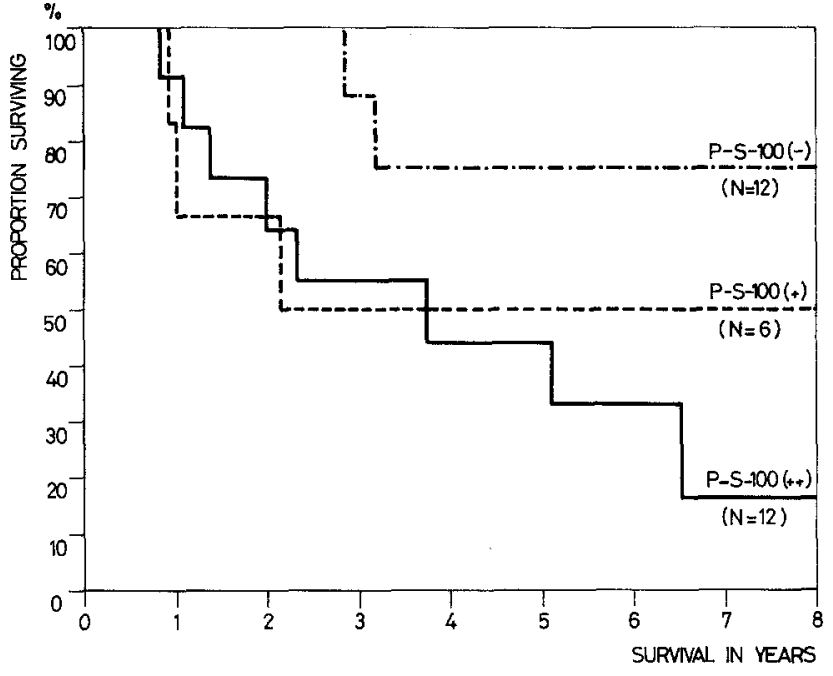

Fig. 2. Kaplan-Meier and Mantel-Haenszel methods. Survival of patients according to density of S-100 protein positive cells in NPC of primary site. Mean survival times were 49 months, 29 months and 38 months for $(-),(+)$, and $(++)$, respectively. Mantel-Haenszel's log-rank test on survival and degree of density of $\mathrm{S}-100$ protein positive cells showed no significant relationship $(p=0,1028 ; p=0,3197$; and $p=0,8493$; when comparing $-/++,-/+$, and $+/++$ cases respectively

These dendritic cells appeared in sliced sections showing PNL as well as HLA-DR positivity, but muramidase negativity displayed a similar topographical distribution as was found with the S-100 immunohistochemical technique.

In relation to the histological variants of NPC, no significant differences were found when correlated with S-100 protein positivity (Table 1). No significant relationship existed between S-100 protein positivity and age or sex of the patients when referred to primary malignancies (Table 2). Furthermore, we conclude that there was no connection between S-100 protein positivity within the tumour and the clinical stage of the patients.

Within the group of 12 primary NPC which were $\mathrm{S}-100$ protein negative, 10 cases were alive (12 months to 84 months survival range) and 2 died (36 months and 37 months respectively). Among the NPC group of primary location, designated as $(+)$ because of the density of S-100 protein reactive cells ( 6 cases), 3 were alive ( 64 months to 84 months survival range) and 3 died $(12,12$ months and 24 months respectively). The group $(++)$ of positivity grade constituted 12 cases, 4 of which were alive (12 months to 84 months survival range) and 8 died (previous survival of the deceased ranged between 12 months to 72 months). The mean survival times were 49 months, 29 months and 38 months for patients with positive 
densities of $(-),(+)$, and $(++)$, respectively. The statistical analysis performed by means of survival curves (Kaplan-Meier's method) failed to demonstrate any positive correlation between level of S100 protein positivity and prognosis. The MantelHaenzel's log - rank test on survival and the degree of the density protein positive cells showed no significant relationship $(p=0.1028 ; p=0.3197$ and $p=0.8493)$ when comparing $-1++,-1+$ and $+/++$ cases respectively (Fig. 2 ).

\section{Discussion}

$\mathrm{S}-100$ is a dimeric calcium - binding protein composed of two subunits (alpha and beta) (Isobe et al. 1978) that was first detected in the nervous system (Moore 1965). Subsequent immunohistochemical studies revealed a wide reactivity in many other tissues (Nakajima et al. 1982; Takahashi et al. 1984) thus S-100 protein reactivity has been found in Schwann cells, melanocytes, salivary gland ductal cells, myoepithelial cells, chondrocytes, T-Lymphocytes and Langerhans' cells.

Within the nasopharyngeal carcinoma (NPC) and in its diverse histological subtypes, several authors (Möller et al. 1984; Lauriola et al. 1984; Bosq et al. 1984; Nomori et al. 1986) have demonstrated the presence of S-100 protein immunoreactive cells. Similarly within our 40 reviewed cases, $60 \%$ of primary site and $100 \%$ of metastatic NPC showed the existence of S-100 protein positive cells displaying dendritic features and intermingled between the tumour cells or sourrounding the epithelial nests.

We confirm, in agreement with other authors, that these cells revealed positivity to peanut lectin (PNL) (Möller et al. 1984), absence of lysozyme or muramidase (Lauriola et al. 1984) (Nomori et al. 1986) and a strong positivity for HLA-DR antigens (Thomas et al. 1984). All these immunohistochemical patterns, together with the dendritic or arachnoid morphological appearance of the S100 protein positive cells, confirmed the nature currently accepted for the Langerhans' or interdigitating reticulum cells in paraffin - embedded material.

The presence of these $S-100$ protein positive cells of Langerhans' type in NPC seems to be of value for several reasons: first it is known that Langerhans' cells play a leading role in the cutaneous cell - mediated immune reaction, intervening in the presentation of antigens to immunocompetent T-lymphocytes (Stingl et al. 1980; SilberbergSinakin et al. 1980). Nasopharyngeal carcinoma (NPC) is usually characterized by a remarkable infiltration of tumour tissue by non-neoplastic lymphoid cells. This associated lymphocyte infiltrate is mainly composed of $T$ cells (Jondal and Klein 1975). NPC represents an intriguing model in human pathology because of the relationship existing between viral infection, neoplastic transformation, and immune response. Perhaps the presence of Langerhans' cells in NPC expresses, as Lauriola et al. 1984 have suggested, involvement of the immune system in the control of EpsteinBarr virus infection and Epstein-Barr virus-associated neoplasms (Epstein and Morgan 1983).

A second point for consideration is the fact that the presence of a large number of Langerhans cells may be related to a better outcome in several skin tumours (Gatter et al. 1984). However, Gisu et al. (1983) have reported that an absence of Langerhans' cells in mycosis fungoides indicates a poorer prognosis. Nomori et al. (1986) in a series of 40 cases of NPC of primary site, suggested that the degree of S-100 protein positive cells is significantly related to prognosis. However in this study we have not been able to confirm any significant relationship between S-100 positivity and the survival of the patients. These apparently contradictory results will require the examination of a larger number of cases of different histological varieties of NPC with a well-known evolution in relation to $\mathrm{S}-100$ protein positivity. In the meantime the significance of the S-100 positive dendritic cells, located in the stroma of the NPC, remains as an immunomorphological finding without clinical relevance of prognostic value. To date no immunohistochemical data seem to express any prognostic value in NPC, the main clinical parameters being those which indicate patient response to therapy.

Acknowledgements. The authors thank J. Ciudad, for the statistical analysis and M. Perez-Bacete, for technical help in the immunohistochemical study as well as S. Perkins for the revision of the English manuscript. The stay of F. Vera-Sempere, in I.G.R. (Villejuif, France) was supported by a Research-Grant from the Ministry of Education and Science, Madrid. Spain.

\section{References}

Bosq J, Gatter KC, Micheau C, Masson DY (1985) Role of immunohistochemistry in diagnosis of nasopharyngeal tumours. J Clin Pathol 38:845-848

Elouaret Y, Micheau C, Bosq J, Caillaud JM, Schwaab G, Tursz T, Sancho-Garnier H, De-Thé G (1986) Classification histo-pronostique des carcinomes indifferencies de type nasopharynge (UCNT). Importance de l'etude du stroma. Ann Otolaryngol Chir Cervicalac 103:145-158

Epstein MA, Morgan AJ (1983) Clinical consequences of Epstein-Barr virus infection and possible control by an antiviral vaccine. Clin Exp Immunol 53:257-271 
Gatter KC, Morris HB, Roach B, Martinez P, Fleming KA, Masson DY (1984) Langerhans' cells and T cells in human skin tumours: an immunohistochemical study. Histopathology $8: 229-244$

Igisu K, Watanabe S, Shimosato Y, Kukita A (1983) Langerhans' cells and their precursos stained with anti S-100 protein antibody in mycosis fungoides. J Clin Oncol 13:693-702

International Union Against Cancer (Union International Contre le Cancer). TNM classification of malignant tumours. Ed 3rd. Geneva, UICC, 1978

Isobe T, Tsugita A, Okuyama T (1978) The amino acid sequence and the subunit structure of bovine brain S-100 protein (PAP 1-b). J Neurochem 30:921-923

Jondal M, Klein G (1975) Classification of lymphocytes in nasopharyngeal carcinoma (NPC) biopsies. Biomedicine 23:163-165

Kaplan EL, Meier P (1958) Non-parametric estimation from incomplete observations. J Am Stat Assoc 53:457-481

Lauriola L, Michetti F, Sentinelli S, Cocchia D (1984) Detection of S-100 labelled cells in nasopharyngeal carcinoma. J Clin Pathol 37:1235-1238

Mantel N, Haenszel W (1959) Statistical aspects of the analysis of data from retrospective studies of disease. J Natl Cancer Inst 22:719-748

Micheau C, De-Thé G, Orofiamma B, Schwaab G, Brugere J, Tursz T, Sancho-Garnier H, Cachin Y (1981) Practical value of classifying NPC in two major microscopical types. In: Grundmann et al. (eds) Nasopharyngeal carcinoma. Cancer Campaign, Vol 5. Gustav-Fischer, New York, Stuttgart, pp 51-57

Micheau C (1986) What's new in histological classification and recognition of nasopharyngeal carcinoma? Pathol Res Pract $181: 249-253$

Möller P, Wirbel R, Hofmann W, Schwechheimer K (1984) Lymphoepithelial carcinoma (Schmincke type) as a derivate of the tonsilar crypt epithelium. Virchows Arch A (Pathol Anat) 405:85-93

Moore BW (1965) A soluble protein characteristic of the nervous system. Biochem Biophys Res Commun 19:739-744

Nadji M, Morales AR (1983) Immunoperoxidase: Part I. The technique and its pitfalls. Lab Med 14:767-771

Nakajima I, Watanabe S, Sato Y, Kameya T, Hirota T, Shimosato $Y$ (1982) An immunoperoxidase study of S-100 protein distribution in normal and neoplastic tissue. Am J Surg Pathol 6:715-727
Nomori H, Watanabe S, Nakajima T, Shimosato Y, Kameya $T$ (1986) Histiocytes in nasopharyngeal carcinoma in relation to prognosis. Cancer 57:100-105

Shaw D, Ho JHC, Fong M, Tsh Ch, Lau WH (1985) Prognosis and histology in Stage I nasopharyngeal carcinoma (NPC). Int J Radiat Oncol Biol Phys 11:893-898

Shanmugaratnam K, Chan SH, De-Thé G, Goh JEH, Khor TH, Simons MJ, Tye CY (1979) Histopathology of nasopharyngeal carcinoma: correlation with epidemiology, survival rate and other biological characteristics. Cancer $44: 1029-1043$

Silverberg-Sinakin I, Gigli I, Baer RL, Thorbecke GJ (1980) Langerhans' cells: Role in contact hypersensitivity and relationship to lymphoid dendritic cells and to macrophages. Immunol Rev 53:203-232

Stefansson IC, Wollman R, Jerkovic M (1982) S-100 protein in soft-tissue tumours derived from Schwann cells and melanocytes. Am J Pathol 106:261-268

Springall DR, Gu J, Cocchia D, Michetti F, Levene A, Levene MM, Marangos PJ, Bloom SR, Polak JM (1983) The value of S-100 immunostaining as a diagnostic tool in human malignant melanomas. Virchows Arch A (Pathol Anat) 400:331-343

Sternberger LA, Hardi PH, Cuculis JJ, Meyer HG (1970) The unlabelled antibody enzyme method of immunohistochemistry. Preparation and properties of soluble antigen-antibody complex (horseradish peroxidase - antihorseradish peroxidase) and its use in identification of spirochetes. $J$ Histochem Cytochem 18:315-333

Stingl G, Tamaki K, Katz SI (1980) Origin and function of epidermal Langerhans' cells. Immunol Rev 53:149-174

Takahashi K, Isobe T, Ohtsuki Y, Akagi T, Sonobe H, Okuyama $T$ (1984) Immunohistochemical study on the distribution of alpha and beta subunits of S-100 protein in human neoplasm and normal tissues. Virchows Arch B (Cell Pathol) $45: 385-396$

Thomas JA, Iliescu V, Crawford DH, Ellouz R, Cammoun M, De-The G (1984) Expression of HLA-DR antigens in nasopharyngeal carcinoma: an immunohistochemical analysis of the tumour cells and infiltrating lymphocytes. Int J Cancer 33:813-819

Accepted March 8, 1987 